\title{
Some Aspects of the Impact that Children (Being Treated at a Psychiatric IIIness) have Upon the Quality of Life of their Parents
}

\author{
Ulrichova Monika ${ }^{1,}$, Brichova Marie ${ }^{2, b}$ \\ University of Hradec Králové, Faculty of Education, Department of Cultural and Religious Studies \\ Rokitanského 62, Hradec Králové, Czech Republic \\ aulrichova.monik@seznam.cz, brichova.marie@uhk.cz
}

\begin{abstract}
Keywords: autism, client, parent, psychiatric care, psychiatric diagnosis
Abstract. Working with children and adolescents who suffer from serious mental illness, lays is very demanding in regards of the care in the whole family. In our paper, we focused mostly on working with autistic children. Childhood autism and schizophrenia are diseases that seriously affect the lives of carers. Given the subject matter and the defined goal of research, qualitative research methods were used. Qualitative approach, namely the use of semi-structured interview, allowed us to obtain detailed description and insight into the lives of the respondents who have a child in psychiatric care.
\end{abstract}

\section{Introduction}

Working with children and adolescents suffering with serious mental illness, is very demanding for treatment in the whole family. This category includes not only children with severe mental retardation or autism, but also young people with tendency to suicidal behaviour, abused children, school phobia, bullying, and lack of social amenities.

Childhood autism is a disease that significantly affects the lives of carers of a disabled child, especially parents. It belongs among the pervasive developmental disorder, characterized by withdrawal and a tendency to social isolation. Mental illness is always a great burden on the whole family. At birth of a disabled child, parents often ask the question "Whose fault is it?". As a consequence, many families cannot cope with the situation and break up. Those families that manage the specific disease, indicate a certain degree of sense that reveals from such a difficult situation. Since we met mostly with parents of autistic children, we will pursue this disease in the paper.

Autism spectrum disorders (hereinafter PAS) were first described in 1943 by an American psychiatrist Leo Kanner. The naming of the disease was inspired by the Greek etymology of the word "autos" that is "alone". Kanner wanted to express this assumption that people with autism are immersed in their own world, lonely and have no interest in the outside world [5]. "The common denominator is a deeper developmental disorder of social interaction and communication than the corresponding mental level of a child "[7].

Among the warning symptoms of PAS belong: difficulty in making eye contact, delayed speech development, reduction or absence of spontaneous interest in the social and physical contact, peculiarities in motor behaviour, specific language expressions.

Sládečková and Sobotková [6] report that the number of diagnosed cases is increasing. The disorder is characterized by a triad of disability in communication skills, social interaction and imaginative thought [3].

Autism is usually diagnosed after the second year of life, but often even in adulthood. [2].

For example Michalová describes that the social behaviour with autism has mostly two poles, pÍ, lonely and extreme. The child either turns away at the desired contact or on the contrary suffer from excessive social activities.

Hyperactivity disorder according to Bazalová combines hyperactive syndrome, mental retardation, stereotypic movements, disruption of attention and self-harm. [1]. According to Thor frequent difficulties that may indicate a pervasive disorder are anxiety, inattention, hyperactivity, emotional immaturity or difficulties in affective regulation. [7]. Michalová states that at early and pre-school age may not be a clinical picture of disorders fully clear. 


\section{Methodology}

The main goal of the research and research sub-goals. The aim of the research is based on interviews to analyse life changes in the values of parents (physical, social, mental and spiritual), who have a child in psychiatric care. A partial goal is to carry out research - to analyse and reflect the attitude of parents in a concrete, agreed psychiatric clinic in Hradec Kralove or in a different psychiatric facility.

- Carry out interviews between a parent of a psychiatric institution client and a student.

- Analyse conditions within a psychiatric facility through observation and interviews with parents and physicians.

- Evaluate the results - analysis of gained data.

- Summary acquired knowledge and their presentation.

Sub-goals are:

- Encourage direct contact of students with patients of a psychiatric facility

- To help parents of psychiatrically treated children's express their needs and ways of support

- Encourage parents psychiatrically treated children

- Inspire the improvement in care for parents of children who are treated in a psychiatric clinic The selected research strategy and its justification. Given the subject matter and to the aim of research, qualitative research methods were implemented. Qualitative approach, namely the use of semi-structured interview, allows obtaining detailed description and insight into the lives of the respondents who have a child in psychiatric care. Semi-structured interview was prepared in advance, during interviews with respondents it was modified and supplemented by new issues in order to obtain comprehensive and specific information.

Questions were focused on the parents' quality of life, focusing on the diagnosis of the child, as well as on changes in the family and family functioning. Other questions investigated the existing support and assistance perceived by parents. Communication with respondents was not aimed at identifying personal initials or specific data on family (names, ages, place of residence) in order to protect and prevent the identification of the respondents.

Justification for choice of research group. Before the start of the research it was determined that the research will only be conducted in one facility. Thanks to the availability and willingness of staff to allow access to patients, psychiatric clinic at the University Hospital in Hradec Kralove was selected. The sample group included parents of children attending regularly to the psychiatric clinic. A total of ten respondents were interviewed, all of whom volunteered to participate in the interview. The facility description. The research was conducted in a specific institution namely at the Psychiatric University Hospital in Hradec Kralove, whose tradition dates back to 1945, when it was established [1]. Psychiatric clinic has 60 acute care beds and 56 aftercare beds. It provides psychiatric emergency and planned care across the spectrum of mental disorders.

In day care centre the clinic provides treatment and rehabilitation of patients with anxiety disorders and those suffering from chronic psychotic disorders. In addition to general outpatient psychiatric surgery the clinic provides outpatient counselling services for the treatment of affective disorders, in child and adolescent psychiatric outpatient clinic, as well as treatment of alcoholism and other addictions. Part of a general psychiatric outpatient surgery is a clinic for the treatment of psychotic disorders and a clinic for sleep disorders. [2]

Psychiatric clinic in which research was conducted, is characterized by a pleasant design, wide corridors and helpful staff. At the end of the waiting room there is a spacious play-room, where toys and books for reading and shortening the time for child patients are available.

The research course. The research was conducted in the months of February to April 2016. Respondents were approached in the waiting room of a psychiatric clinic every time by prior arrangement with the doctor. Actual interview took place subsequently in a room separated from a psychiatric clinic. The doctor has identified parents who might be willing to participate in research.

Before starting the interview, every participant was informed about the intention of the research and advised on procedures for the processing of their notice. Respondents were also familiar with the 
fact that they may at any time terminate their participation in research. All needed information was stated in the consent form, which was signed by the respondent and the conductor of research. The interviews were recorded on the recording device and then word for word transcribed into electronic form. Respondents agreed with the content of research and the possibility of interview recording.

Based on the analysis of transcript texts, categories were created according to individual diagnoses. Individual diagnoses have been further specified with additional information e.g. the stage of diagnosis acceptance, changes in family or support and assistance in the family.

\section{Results}

First, it should be pointed out that we came across some difficulties in a conducted research. The research is limited by the low number of research respondents. The quality of the notice and conclusions of the investigation is influenced by the degree of openness and honesty of respondents. Since research is based on the subjective statements of individuals, it is not possible to generalize the findings.

Respondents involved in research raise children with the following psychiatric diagnosis - autism (Asperger's syndrome), mental retardation, ADHD and anxiety disorders and other diagnoses.

When comparing the individual cases it is evident that the impact of the child on the family varies according to diagnosis. Most families and their functioning is affected by the diagnosis of autism and anxiety disorders.

This finding is also influenced by the stage of the diagnosis adoption, in which the family is. In families where they live with the diagnoses for a longer time, the diagnoses is not reflected as a problem, but as a way of life. In families where they the child has been diagnosed recently, there appears a feeling of disappointment, sadness, a fear that they cannot handle the situation, and the idea of how the future will look like. We can assume that families that are now diagnostically comparable, experienced in the past after the diagnosis has been confirmed, the same feelings and fears. Likewise, these families might fully cope with the diagnoses of their child in the future.

For all diagnoses reported by respondents, there occurs generational misunderstanding on the part at least one of the grandparents. There is a contradiction between the opinion of doctors and the perception of grandparents, who think that children can be raised, everything is just a matter of upbringing. On the other hand, grandparents are frequently those in the family who provide the necessary support and assistance.

Fundamental changes in family functioning can occur in families with a diagnosis of autism. The most affected is leisure time and daily routine of all family members. For other diagnoses restrictions on family functioning is not as crucial as described by the respondents.

Parents of children with ADHD do not experience large changes in family functioning, and some have a feeling that this is not a serious diagnosis which should be burdensome for the family. In all families occurs stress that comes from challenging upbringing of the child.

\section{Conclusion}

We are aware that due to the small number of respondents involved in the research findings cannot be generalized, yet they present some insight into the issue. To uncover all aspects affecting the life quality of families raising a child with a psychiatric diagnosis, further investigation would be required.

Respondents who participated in the survey, had no problem to talk on the topic of upbringing a child with a psychiatric disorder. Ten respondents, who have a child attending psychiatric practice, participated in the research. Through analysis of interviews related to the life quality of families who have a child in psychiatric care, we came to the conclusions described in chapter Results. Generally we can say that the quality of life of members of families where a child with serious mental illness is brought up, is largely influenced by this fact. Families in the early stages of diagnosis have many 
problems to cope with the new situation, while families that have already gone through this stage are able to set their own pace of life and do not consider the situation to be such a burden.

According to parents' statements, more psychological support by experts, who would work on the improvement of the family well-being, would be very helpful. In this way there could be prevented mental strain or stress that arises in connection with the intensive raising of the child in psychiatric care.

\section{Acknowledgements}

This paper was financially supported by the University of Hradec Králové Specific Research project 2016.

\section{References}

[1] Bazalová, B.: Poruchy autistického spektra: teorie, výzkum, zahraniční zkušensoti. $1^{\text {st }}$ Issue. Brno: Masarykova univerzita, (2011), p. 78-79.

[2] Coleman, M.-Gillberrg, Ch. The autisms. 4ed. Oxford Univerzity Press (2012), p. 12.

[3] Chan, J.-John,R.M. :Sexuality and Sexual Health in Children and Adolescents with Autism. The Journal for Nurse Practitioners Vol. 8 (on line) (2012), p.306

[4] Michalová, Z.: Sociální dovednosti u žáků s poruchami autistického spektra se zaměřním na ovlivnění chováni., $1^{\text {st }}$ Issue. Liberec. Technická Univerzita v Liberci, (2011), p.93.

[5] Ř́hová, A.: Poruchy autistického spektra. $1^{\text {st }}$ Issue. Olomouc: Univerzita Palackého v Olomouci (2011), p.10.

[6] Sládečková, S. - Sobotková, I: Dětský autismus v kontextu rodinné resilience. $1^{\text {st }}$ Issue. Olomouc: Univerzita Palackého v Olomouci(2014), p. 22-23.

[7] Thorová, K.: Poruchy autistického spektra: dětský autismus, atypický autismus, Aspergerův syndrome desintegrační porucha. $1^{\text {st }}$ Issue. Praha: Portál, (2008), p. 19. 